\title{
Kamkat tozunun fizikokimyasal özellikleri üzerine farklı kurutma uygulamalarının etkisi
}

\section{Effect of different drying treatments on the physicochemical properties of kumquat powders}

\author{
Demet YILDIZ TURGUT ${ }^{* 1}$ iD, Arzu BAYIR YEĞiN ${ }^{1}$ iD \\ ${ }^{1}$ Batı Akdeniz Tarımsal Araştırma Enstitüsü Müdürlüğü, 07100, Antalya, Türkiye
}

To cite this article:

Yıldız Turgut, D. \& Bayır Yeğin, A. (2019). Kamkat tozunun fizikokimyasal özellikleri üzerine farklı kurutma uygulamalarının etkisi. Harran Tarım ve Gıda Bilimleri Dergisi, 23(4): 477-488. DOI: $10.29050 /$ harranziraat.569808

Address for Correspondence: Demet YILDIZ TURGUT e-mail:

demet.yildizturgut@tarimorman.gov.tr

Received Date:

24.05.2019

Accepted Date:

17.09.2019
(C) Copyright 2018 by Harran University Faculty of Agriculture. Available on-line at www.dergipark.gov.tr/harranziraat

This work is licensed under a
Creative Commons

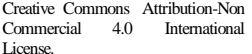

\section{öz}

Bu çalışmada farklı kurutma uygulamalarının kamkat tozlarının fizikokimyasal özelliklerine etkisinin incelenmesi amaçlanmıştır. Püre haline getirilmiş kamkat meyveleri \%10 maltodekstrin ilaveli ve maltodekstrinsiz olmak üzere sıcak hava kurutma (SHK) ve dondurarak kurutma (DK) yöntemi ile kurutulmuş ve toz haline getirilmiştir. Elde edilen kamkat tozlarında nem içeriği, su aktivitesi, renk değerleri, ıslanabilirlik, çözünürlük, yığın yoğunluğu, sıkıştırılmış yoğunluk, akabilirlik ve yapışkanlık özellikleri belirlenmiştir. En düşük nem içeriği (\%10.32) ve su aktivitesi değeri (0.106) maltodekstrin ilaveli dondurarak kurutma yöntemi ile elde edilen örnekte belirlenmiştir. Sıcak hava ile kurutulan örneklerin taze meyve püresinin renk değerlerine en yakın özellikte olduğu tespit edilmiştir. Örneklerin ıslanabilirlik ve çözünürlük süreleri sırasıyla 196-450 s ve 230-414 s olarak belirlenmiştir. Kamkat tozlarının yığın ve sıkıştırılmış yoğunluk değerleri sırasıyla 0.27-0.70 $\mathrm{g} \mathrm{ml}^{-1}$ ve 0.39-0.77 $\mathrm{g} \mathrm{ml}^{-1}$ olup, en yüksek değerler sıcak hava ile kurutulan örneklerde tespit edilmiştir. Maltodekstrin ilaveli sıcak hava kurutma yöntemi ile elde edilen toz örneğinin çok iyi akabilirlik ve düşük yapışkanlık özelliği gösterdiği belirlenmiştir.

Anahtar Kelimeler: Kamkat, Meyve tozu, Maltodekstrin, Sıcak hava kurutma, Dondurarak kurutma

\section{ABSTRACT}

This study was aimed to investigate the effect of different drying treatments on the physicochemical properties of kumquat powders. The kumquat fruit puree was dried by hot air drying (HAD) and freeze drying (FD) methods with $10 \%$ of maltodextrin and without maltodextrin, and the dried puree was powdered. The moisture content, water activity, color values, wettability, solubility, bulk density, tapped density, flowabilty and cohesiveness properties were determined in the kumquat powders. The minimum moisture content $(10.32 \%)$ and water activity $(0.106)$ were determined in the samples from obtained by freeze drying method with maltodextrin. It was found that the color values of the hot air dried samples were the closest to the color values of the fresh fruit puree. The wettability and solubility times ranged between 196-450 s and 230-414 s, respectively. The bulk and tapped density values of kumquat powders were determined as $0.27-0.70 \mathrm{~g} \mathrm{ml}^{-1}$ and $0.39-0.77 \mathrm{~g} \mathrm{ml}^{-1}$, respectively and the highest bulk and tapped density values were found in the hot air dried powders. Hot air dried powders with maltodextrin exhibited a very good flowability and low cohesiveness.

Key Words: Kumquat, Fruit powder, Maltodextrin, Hot air drying, Freeze drying
Giriş

Meyve tozları kullanım kolaylıkları, ambalajlama, depolama ve taşıma masraflarının azaltılması ve raf ömrünün uzatılması gibi avantajları nedeniyle gıda endüstrisinde önemli bir yere sahiptir (Saifullah ve ark., 2016). Meyve 
tozları içecek üretiminde ara ürün olarak değerlendirilmesinin yanı sıra, gıda maddelerinin besinsel özelliklerini geliştirmek amacıyla fonksiyonel gıda katkı maddesi, ve yoğurt, dondurma, meyve barı gibi ürünlerde aroma maddesi ve renklendirici olarak kullanılmaktadır (Karam ve ark., 2016).

Meyvelerin toz forma dönüştürülmeleri, meyve suyunun, pulpunun veya meyvelerin bütün olarak kurutulup öğütülmesi ile gerçekleştirilmektedir (Michalska ve ark., 2016; Zoric ve ark., 2017; Araujo-Díaz ve ark., 2017; Dantas ve ark., 2018). Meyvelerin bileşimlerinde yer alan sakkaroz, glukoz ve fruktoz gibi düşük molekül ağırlıklı şekerler ile organik asitler bu ürünlerin toz forma işlenmesi, muhafazası ve diğer ürünlerde kullanımı sırasında bir takım problemlere neden olabilmektedir. Bu problemlerin başında yapışkanlık, kekleşme ve higroskopi gelmektedir (Jay ve Das, 2009). Bu bileşenler suda çözünür özellikte olup, amorf halde iken oldukça higroskopiktir ve düşük camsı geçiş sıcaklığına sahiptirler. Toz ürünlerin üretimi sırasında sistemin camsı geçiş sıcaklığını düşürürler ve kurutmada uygulanan sıcaklıklara bağlı olarak yapışkanlık meydana gelir (Sablani ve ark., 2008; Jay ve Das, 2009). Bu sorunların önüne geçebilmek için meyve suyu veya pulpuna kurutma öncesi çeşitli taşıyıcı ajanlar eklenmektedir. Maltodekstrin ve arabik gam endüstride en çok kullanılan taşıyıcı ajanlardır. Bunların dışında meyve tozu üretiminde kekleşmeyi önleyici olarak trikalsiyum fosfat, silikon dioksit, silikatlar, fosfatlar, protein izolatları, stearik asit tuzları ve modifiye karbonhidratlar gibi maddeler de kullanılmaktadır. Bu bileşenlerin genel özelliği camsı geçiş sıcaklığını arttırarak yapışkanlığı önlemeleridir. Ayrıca toz ürünlerin çözünürlük ve akışkanlık gibi fiziksel özelliklerini geliştirirler. Bunun dışında meyvelerde yer alan biyoaktif bileşenlerin oksidasyonla kaybını önemli oranda engelleyebilirler (Sablani ve ark., 2008; Ferrari ve ark., 2013; Tontul ve Topuz, 2017; Michalska ve ark., 2018). Bu materyallerin optimum kullanım miktarı meyvenin çeşidi ile fiziksel ve kimyasal kompozisyonuna göre değişebilmektedir (Sablani ve ark., 2008). Maltodekstrin nişastanın hidrolizi ile elde edilen, glikozidik bağlarla bağlanmış Dglukoz ünitelerini içeren bir oligosakkarittir (Suravanichnirachorn ve ark., 2018). Ucuz olması, nötral tat ve aromaya sahip olması, iyi bir nem bariyeri olması ve biyoaktif bileşenleri koruması gibi avantajları nedeniyle meyve tozu üretiminde yaygın şekilde tercih edilmektedir (Ballesteros ve ark., 2017; Dağ ve ark., 2017; Silva ve ark., 2018). Maltodekstrinin farklı meyvelerden elde edilen toz ürünlerde fizikokimyasal ve fitokimyasal özellikleri olumlu etkilediği yönünde çalışmalar mevcuttur (Ferrari ve ark., 2012; Suravanichnirachorn ve ark., 2018; Michalska ve ark.,2018).

Meyve tozlarının kalitesi büyük ölçüde hammaddenin fiziksel ve kimyasal özellikleri ile kurutma ve öğütme koşullarından etkilenmektedir (Sablani, 2006; Rahman ve ark., 2009; Sablani ve ark., 2011, Karam ve ark. 2016). Meyve tozu üretiminde en yaygın kullanılan kurutma yöntemi püskürterek kurutmadır. Bunun dışında dondurarak kurutma, sıcak hava kurutma ve vakum kurutma gibi yöntemler de kullanılmaktadır (Wang ve ark., 2007; Saifullah ve ark., 2016; Si ve ark., 2015; İslam ve ark., 2017).

Kamkat turunçgillerle aynı familyada (Rutaceae) yer alan, ancak farklı cins (Fortunella) içinde değerlendirilen bir bitki türüdür. Meyvesi taze olarak kabuğu ile birlikte tüketilebilmekte, bunun dışında reçel, marmelat, likör, şekerleme, turşu ve kurutulmuş ürün proseslerinde değerlendirilmektedir (Sadek ve ark., 2009; Wang ve ark., 2012; Lou ve ark., 2015). Kamkat meyvesi sağlığa faydalı askorbik asit, flavonoidler, karotenoidler ve uçucu yağ açısından zengin bir meyvedir (Güney ve ark., 2014). Son yıllarda fonksiyonel özellikleri nedeniyle turunçgil meyvelerinin kurutularak toz forma dönüştürülmesi ile ilgili çalışmalar artış göstermektedir (Chegihi ve Ghobadion, 2005; Kang ve ark., 2006; Goulo ve Adamopoulos, 2010; Kadam ve ark., 2011; Garcia-Salas ve ark., 2013; Gabriele ve ark., 2017; Agudelo ve ark., 2017; İslam ve ark., 2017). Bu çalışmada ülkemizde 
yaygın olarak Akdeniz bölgesinde yetiştirilen kamkat meyvesinin toz ürüne işlenebilme olanakları araştırılarak, farklı kurutma uygulamalarının elde edilen toz ürünlerin fizikokimyasal özelliklerine etkisi değerlendirilmiştir.

\section{Materyal ve Metot}

Bu çalışmada "Oval" olarak da bilinen "Nagami" çeşidine ait kamkat meyveleri kullanılmıştır. Meyveler, 2017 yılı hasat döneminde Antalya ilinde bulunan Batı Akdeniz Tarımsal Araştırma Enstitüsü'ne ait turunçgil bahçelerinden toplanmıştır. Hasat edilen meyveler, saf su ile yıkanarak, çekirdekleri çıkarılmış ve TEFAL MB450141 model bıçaklı doğrayıcıda püre haline getirilmiştir. Kurutma öncesi, elde edilen püre iki gruba ayrılarak, pürenin bir kısmına püre ağırlığı üzerinden $10 \mathrm{DE}$ (Dektroz eşdeğeri) \%10 maltodekstrin ilave edilmiş, diğer kısmına hiçbir madde eklenmemiştir. Püreler cam petrilere kalınlığı 3 $\mathrm{mm}$ olacak şekilde koyularak sıcak hava kurutma (SHK) ve dondurarak kurutma (DK) olmak üzere 2 farklı kurutma yöntemiyle kurutulmuştur. Sıcak hava ile kurutma yönteminde laboratuar tipi sıcak hava kurutma fırını (EKSiS Endüstriyel Kurutma Sistemleri Limited Şirketi, Isparta) kullanılmış ve işlem $65^{\circ} \mathrm{C}$ hava sıcaklığında, $1 \mathrm{~m} \mathrm{~s}^{-1}$ sabit hava hızında 7 saat sürede gerçekleştirilmiştir. Örneklerin dondurarak kurutulması, liyofilizatörde (Christ Beta 2-8 LD plus) iki aşamada gerçekleştirilmiştir. İşlem ilk aşama $18^{\circ} \mathrm{C}^{\prime} \mathrm{de}, 1.2 \mathrm{mbar}$ basınçta $30 \mathrm{dk}$, ikinci aşama $60^{\circ} \mathrm{C}^{\prime} \mathrm{de}, 0.011$ mbar basınçta 20 saat süre ile sürdürülmüştür. Kurutulmuş örnekler Retsch GRINDOMIX GM 200 model bıçaklı öğütücüde 10.000 rpm sabit hızda $1 \mathrm{dk}$ süre ile öğütülmüştür.

\section{Analizler}

Nem Tayini

Toz örneklerin nem içerikleri AOAC (2000) (Metot 986.21) nem tayin yöntemine göre belirlenmiştir. Bu yöntemin prensibi, su ile karışmayan organik bir çözücü ile üründeki suyun damıtma yöntemi ile miktarının belirlenmesidir. Bir cam balon içerisine $10 \mathrm{~g}$ örnek alınmış ve üzerini örtecek miktarda ksilen ilave edilmiştir. Cam balon ısıtıcı cihaza yerleştirilmiş, cihazın dereceli bölümüne balon içerisine akacak şekilde ksilen koyulmuş ve ısıtıcı çalıştırılmıştır. Damıtma işlemi dereceli bölmede biriken su seviyesi sabit kalana kadar sürdürülmüştür. Ardından dereceli bölmede biriken suyun hacmi okunarak aşağıdaki verilen 1 No'lu eşitlik ile nem içeriği \% (yüzde) olarak hesaplanmıştır. Burada $\mathrm{V}$ biriken suyun hacmi (ml) ; $M$ ise analize alınan örnek kütlesidir (g).

$\operatorname{Nem}(\%)=(V / M) \times 100$

\section{Su aktivitesi}

Toz örneklerin su aktivitesi değerleri su aktivitesi ölçüm cihazı (Novasina Lab-swift) yardımıyla $25^{\circ} \mathrm{C}^{\prime}$ de belirlenmiştir.

\section{Renk Değerleri}

Toz örneklerin CIE $L^{*}, a^{*}, b^{*}$ renk değerleri Minolta CR 400 (Osaka, Japonya) marka renk cihazı ile belirlenmiştir. Belirlenen $L^{*}, a^{*}, b^{*}$ değerlerinden aşağıda verilen 2,3 ve 4 No'lu eşitlikler ile $C^{*}$ (kroma, renk doygunluğu), $h^{\circ}$ (hue açısı, renk yoğunluğu açısı) ve TRD (Toplam renk değişimi) hesaplanmıştır (Dağ ve ark., 2017). TRD' nin belirlenmesinde meyve püresinde ölçülen $L^{*}$, $a^{*}$ ve $b^{*}$ değerleri referans alınmıştır.

$$
\begin{aligned}
& C^{*}=\sqrt{a^{*} 2+b^{* 2}} \\
& h^{\circ}=\tan ^{-1} \frac{b^{*}}{a^{*}} * \frac{180}{\pi} \\
& T R D=\sqrt{\left(\Delta L^{*}\right)^{2}+\left(\Delta a^{*}\right)^{2}+\left(\Delta b^{*}\right)^{2}}
\end{aligned}
$$

\section{Islanabilirlik analizi}

$10 \mathrm{~g}$ meyve tozunun; $100 \mathrm{ml} 25^{\circ} \mathrm{C}^{\prime}$ de distile suyun içerisinde tamamen çöktüğü sürenin $\mathrm{s}$ (saniye) olarak kaydedilmesi ile gerçekleştirilmiştir (Gong vd., 2008).

\section{Çözünürlük analizi}

$2 \mathrm{~g}$ meyve tozunun $50 \mathrm{ml} 30{ }^{\circ} \mathrm{C}^{\prime}$ deki saf su 
içerisinde sabit hızda manyetik karıştırıcı ile tamamen çözününceye kadar geçen süre (s) olarak belirlenmiştir (Goula and Adamopoulos, 2008).

\section{Yığın yoğunluğu}

Kamkat tozu örneklerinin yığın yoğunluğu Jinapong ve ark. (2008) tarafından önerilen yöntemle, 100 ml'lik cam silindire $100 \mathrm{ml}$ çizgisine kadar meyve tozu koyularak, kütle/ hacim oranıyla hesaplanmıştır (Jinapong vd., 2008).

\section{Sıkıştırılmış yoğunluk}

Toz örneklerin sıkıştırılmış yoğunluğu miktarı bilinen toz materyalin ağırlığının bir kapta belli sayıda vuruş darbeleriyle sıkıştırılarak hacmindeki değişime göre hesaplanmaktadır. Bu amaçla $2.5 \mathrm{~g}$ toz kütlesi $10 \mathrm{ml}$ cam silindir içerisinde, $100 \mathrm{kez}$ vuruş darbesiyle sıkıştırılmış ve silindirde ölçülen hacim kaydedilerek kütle/hacim oranıyla hesaplanmıştır (Saifullah ve ark., 2016).

\section{Carr Indeks (Ci) ve Hausner Oranı ( $\mathrm{HO})$}

Akışkanlık ve yapışkanlık özelliklerinin belirlenmesi Carr Index $(\mathrm{Cl})$ ve Hausner Oranına
(HR) göre değerlendirilmiş ve bu değerler Eşitlik 5 ve 6 yardımıyla hesaplanmıştır (İslam ve ark., 2017).

\section{$C i=\quad[S ı k ı s ̧ t ı r ı l m ı s ̧ ~ y o g ̆ u n l u k-$}

(Kütle yoğunluğu/Sıkıştırılmış yoğunluk)]*100 $H O=$ Sıkıştırılmış yoğunluk/Kütle yoğunluğu

\section{istatistiksel analiz}

Meyve tozu üretimleri 3 tekrarlı olarak gerçekleştirilmiştir. Analiz verilerine varyans analizi uygulanmış ve önemli sonuçlar $\mathrm{P}<0.05$ düzeyinde Duncan çoklu karşılaştırma testine tabi tutulmuştur. Analizde SAS istatistik paket programı (Version 6.12, SAS Institute, Cary, NC, ABD) kullanılmıştır. Sonuçlar ortalamaıstandart sapma olarak verilmiştir.

\section{Araştırma Bulguları ve Tartışma}

Araştırmada farklı kurutma uygulamaları ile elde edilen kamkat tozları (Şekil 1.) nem içeriği, su aktivitesi, renk değerleri ile toz ürünlere özgü bazı fiziksel özellikler açısından incelenmiştir.

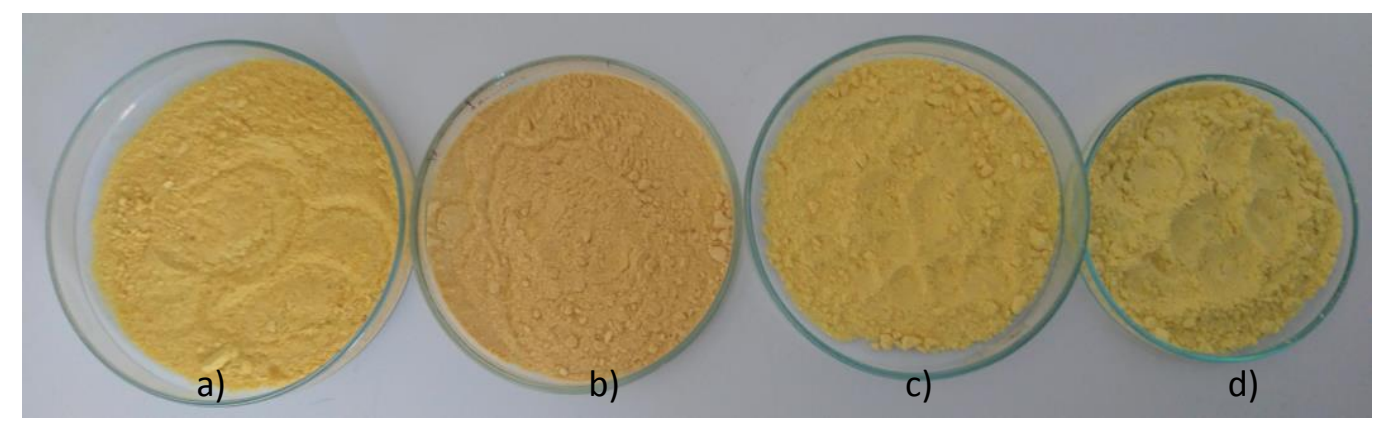

Şekil 1. Kamkat tozu örnekleri; a)Maltodekstrin ilaveli-SHK; b)Maltodekstrinsiz-SHK; c) Maltodekstrin ilaveli-DK; d) Maltodekstrinsiz-DK

Figure 1. Kumquat powder samples a) With maltodextrin-HAD; b) Without maltodextrin-HAD c) With maltodextrin- $F D$; d) Without maltodextrin-FD

Kamkat tozlarının nem miktarı damıtma yöntemi ile belirlenmiştir. Bu yöntem uçucu yağ içeren ürünlerin nem miktarının belirlenmesinde yaygın olarak kullanılmaktadır. Kamkat meyvesinin kabuk kısmı önemli oranda uçucu yağ içermektedir (Wang ve ark., 2012). Örneklerin nem içerikleri Çizelge 1 'de verilmiş olup, \%10.32-
12.94 arasında tespit edilmiştir. En yüksek nem içeriği maltodekstrinsiz DK yöntemi ile kurutulan örnekte, en düşük nem içeriği maltodekstrin ilaveli DK yöntemi ile kurutulan örnekte belirlenmiştir $(\mathrm{P}<0.05)$. Her iki kurutma yönteminde maltodekstrin ilaveli örneklerin daha düşük nem içeriğine sahip olduğu tespit edilmiştir. 
Ferrari ve ark. (2012) meyve tozlarında taşıyıcı ajan olarak maltodekstrin kullanımının nem içeriğini azaltıcı etki yaptığına vurgu yapmışlardır. İslam ve ark. (2016), farklı maltodekstrin oranları ve kurutma yöntemleri ile portakal suyundan elde edilen meyve suyu tozlarında nem içeriğini \%3.064.18 olarak tespit etmişler ve maltodekstrin konsantrasyonunun arttırılması ile toz ürünün nem içeriğinin azaldığını rapor etmişlerdir. Michalska ve ark. (2016) farklı kurutma yöntemleri (dondurarak kurutma, vakum kurutma, konvektif kurutma, vakum-mikrodalga kurutma, konvektif- mikrodalga kurutma) ile elde ettiği erik tozlarında nem değerlerini \%2.4-8.8 arasında tespit etmiş ve en yüksek değeri dondurarak kurutma yönteminde belirlemiştir. Çalışmamızda tespit edilen nem içerikleri literatür değerlerinden farklıdır. Bu farklılık meyvenin çeşidi, kurutma yöntemi ve taşıyıcı ajan konsantrasyonu gibi faktörlerden kaynaklanmaktadır.

Kamkat tozu örneklerinin su aktivitesi değerleri 0.106-0.282 arasında değişim göstermiştir $(P<0.05)$. Nem içeriğine benzer şekilde, en yüksek su aktivitesi değeri maltodekstrinsiz DK ile kurutulan örnekte, en düşük su aktivitesi değeri ise maltodekstrin ilaveli DK ile kurutulan örnekte tespit edilmiştir. Yapılan bir çalışmada farklı kurutma yöntemleri ve maltodekstrin konsantrasyonlarında elde edilen portakal suyu tozu örneklerinde su aktivitesi değerleri 0.20-0.27 arasında belirlenmiştir (İslam ve ark., 2017). Kivi, ayva ve balkabağı pürelerinin $\% 10$ maltodekstrin ilaveli dondurarak kurutulması ile elde edilen meyve tozlarının su aktivitesi değerleri 0.2250.273 arasında belirlenmiştir. (Dirim ve ark., 2015). 4 farklı kurutma yöntemi ile elde edilen mango tozu örneklerinde su aktivitesi değerleri 0.169-0.177 arasında değişmiştir (Caparino ve ark., 2012). Bir başka çalışmada ise balkabağı püresinin dondurarak kurutulması ile elde edilen meyve tozunda su aktivitesi değeri 0.197 olarak tespit edilmiştir (Dirim ve Çalışkan, 2012). Su aktivitesi kurutulmuş ürünlerin depolama stabilitesi açısından önemli bir kalite faktörüdür. 0.20-0.40 arasındaki su aktivitesi değerlerinde esmerleşme ve hidrolitik reaksiyonlar, lipit oksidasyonu, enzimatik aktiviteye karşı ürün stabilitesi sağlanabilmektedir (Dirim ve Çalışkan, 2012). Genel olarak su aktivitesi değerinin 0.60'ın altında olması durumunda gıda maddelerinin mikrobiyolojik olarak stabil olduğu kabul edilmektedir (Quek ve ark., 2007). Su aktivitesi değeri 0.30 'dan düşük olan toz ürünler kimyasal ve mikrobiyolojik stabilite açısından güvenli olarak kabul edilmektedir (Tontul ve Topuz, 2017). Çalışmamızda meyve tozu örneklerinde belirlenen su aktivitesi değerleri literatür değerleri ile uyumlu olup, mikrobiyolojik ve kimyasal reaksiyonlar açısından güvenli sınırlar içerisindedir.

Çizelge 1. Kamkat tozlarının nem içerikleri ve su aktivitesi değerleri*

Table 1. The moisture content and water activity of kumquat powders*

\begin{tabular}{|l|c|c|}
\hline $\begin{array}{l}\text { Kurutma uygulamaları } \\
\text { Drying Treatments }\end{array}$ & $\begin{array}{c}\text { Nem İçeriği } \\
(\%) \\
\text { Moisture } \\
\text { content (\%) }\end{array}$ & $\begin{array}{c}\text { Su aktivitesi } \\
\text { Water } \\
\text { activity }\end{array}$ \\
\hline $\begin{array}{l}\text { Maltodextrin ilaveli }- \text { SHK } \\
\text { With maltodextrin-HAD }\end{array}$ & $10.49 \pm 0.02^{\mathrm{c}}$ & $0.211 \pm 0.003^{\mathrm{c}}$ \\
\hline $\begin{array}{l}\text { Maltodekstrinsiz -SHK } \\
\text { Without maltodextrin-HAD }\end{array}$ & $11.84 \pm 0.03^{\mathrm{b}}$ & $0.221 \pm 0.004^{\mathrm{b}}$ \\
\hline $\begin{array}{l}\text { Maltodekstrin ilaveli }-\mathrm{DK} \\
\text { With maltodextrin-FD }\end{array}$ & $10.32 \pm 0.02^{\mathrm{d}}$ & $0.106 \pm 0.003^{\mathrm{d}}$ \\
\hline $\begin{array}{l}\text { Maltodekstrinsiz -DK } \\
\text { Without maltodextrin-FD }\end{array}$ & $12.94 \pm 0.03^{\mathrm{a}}$ & $0.282 \pm 0.004^{\mathrm{a}}$ \\
\hline
\end{tabular}

*Aynı sütundaki farklı harfler ortalamalar arasındaki farklıı̆̆ın $\mathrm{P}<0.05$ düzeyinde önemli olduğunu gösterir. SHK: Sıcak hava kurutma; DK: Dondurarak kurutma.

Different letters in the same column indicate that the differences between the means are significant at $P<0.05$. HAD: Hot air drying; FD: Freeze drying.

Çalışma sonucunda elde edilen kamkat tozlarının renk değerleri Çizelge 2'de yer almaktadır. Kurutma öncesi kamkat meyve püresinde $L^{*}, a^{*}$ ve $b^{*}$ değerleri sırasıyla $61.36 \pm 1.33,4.43 \pm 2.12$ ve $54.00 \pm 1.76$ olarak tespit edilmiştir. $C^{*}$ ve $h^{\circ}$ değerleri ise $54.18 \pm 1.58$ ve $85.31 \pm 2.54$ 'tür. $L^{*}$ değerleri taze meyveye göre artış göstermiş olup, 75.47-87.12 arasında tespit edilmiştir. En yüksek $L^{*}$ değeri maltodekstrinsiz DK yöntemi ile kurutulan örneklerde, en düşük $L^{*}$ değerleri ise SHK yöntemi ile kurutulan örneklerde belirlenmiştir $(P<0.05)$. $L^{*}$ değerinin artışı parlaklık derecesinin artışıyla 
açıklanmaktadır (Oliveira ve ark., 2015). Michalska ve ark. (2016) farklı kurutma yöntemleri ile elde edilen erik tozlarında $L^{*}$ değerinin taze meyve püresine göre artış gösterdiğini, en yüksek değerin vakum kurutma yönteminde elde edildiğini bildirmiştir. Çalışmamızda en yüksek $L^{*}$ değeri dondurarak kurutulmuş örneklerde belirlenmiştir. Dondurarak kurutma ve maltodekstrin ilavesinin oksidasyonu engelleyerek parlaklığı koruduğu veya arttırabildiği bildirilmiş ve $L^{*}$ değerindeki benzer değişimler balkabağı ve kivi meyve tozunda ortaya konmuştur (Dirim ve ark., 2015). Maltodekstrin, arabik gam, aljinat ve pektin gibi farklı oranlarda ve kombinasyonlarda dondurarak kurutulmuş altın çilek meyve suyu tozlarında, taze meyve suyuna göre $L^{*}$ değerleri artış göstermiştir (Dağ ve ark., 2017). Farklı kurutma yöntemlerinin kullanıldığı amla meyve tozu örneklerinde en yüksek L* değeri dondurarak kurutma yöntemi ile elde edilen örneklerde belirlenmiştir (Mishra ve ark., 2009).

Table 2. The color values of kumquat powders*

\begin{tabular}{|c|c|c|c|c|c|c|}
\hline $\begin{array}{l}\text { Kurutma } \\
\text { uygulamaları } \\
\text { Drying treatments }\end{array}$ & $\begin{array}{l}\mathrm{L}^{*} \\
L^{*}\end{array}$ & $\begin{array}{l}a^{*} \\
a^{*}\end{array}$ & $\begin{array}{l}\mathrm{b}^{*} \\
b^{*}\end{array}$ & $\begin{array}{l}C^{*} \\
C^{*}\end{array}$ & $\begin{array}{l}h^{\circ} \\
h^{\circ}\end{array}$ & $\begin{array}{l}\text { TRD } \\
T C C\end{array}$ \\
\hline $\begin{array}{l}\text { Maltodekstrin ilaveli } \\
\text {-SHK } \\
\text { With maltodextrin- } \\
\text { HAD }\end{array}$ & $75.96 \pm 0.55^{c}$ & $3.49 \pm 0.11^{c}$ & $54.14 \pm 0.36^{b}$ & $54.25 \pm 0.36^{b}$ & $86.31 \pm 0.14^{b}$ & $14.63 \pm 0.55^{c}$ \\
\hline $\begin{array}{l}\text { Maltodekstrinsiz - } \\
\text { SHK } \\
\text { Without } \\
\text { maltodextrin-HAD }\end{array}$ & $75.47 \pm 0.20^{c}$ & $4.59 \pm 0.19^{a}$ & $54.98 \pm 0.06^{\mathrm{a}}$ & $55.17 \pm 0.06^{a}$ & $85.22 \pm 0.20^{c}$ & $14.15 \pm 0.19^{c}$ \\
\hline $\begin{array}{l}\text { Maltodekstrin ilaveli } \\
\text {-DK } \\
\text { With maltodextrin- } \\
\text { FD }\end{array}$ & $84.57 \pm 0.16^{b}$ & $-1.36 \pm 0.2^{d}$ & $47.90 \pm 0.06^{c}$ & $47.92 \pm 0.07^{c}$ & $88.37 \pm 0.27^{\mathrm{a}}$ & $24.69 \pm 0.19^{b}$ \\
\hline $\begin{array}{l}\text { Maltodekstrinsiz - } \\
\text { DK } \\
\text { Without } \\
\text { maltodextrin-FD }\end{array}$ & $87.12 \pm 0.041^{a}$ & $4.10 \pm 0.02^{b}$ & $41.91 \pm 0.09^{d}$ & $42.130 .07 d$ & $84.40 \pm 0.04^{d}$ & $28.45 \pm 0.07^{\mathrm{a}}$ \\
\hline
\end{tabular}

*Aynı sütundaki farklı harfler ortalamalar arasındaki farkııı̆ıı $\mathrm{P}<0.05$ düzeyinde önemli olduğunu gösterir. SHK: Sıcak hava kurutma; DK: Dondurarak kurutma.

* Different letters in the same column indicate that the differences between the means are significant at $P<0.05$. HAD: Hot air drying; FD:

Freeze drying.

Kamkat tozu örneklerinin a* değerleri (-)1.394.59 arasında belirlenmiştir. En yüksek a* değeri maltodekstrinsiz SHK yöntemi ile kurutulan örneklerde, en düşük a* değeri ise maltodekstrin ilaveli DK yöntemi ile kurutulan örneklerde tespit edilmiştir $(P<0.05)$. Pozitif $a^{*}$ değeri kırmızılığın artışına işaret ederken, negatif a* değerleri grimsi tonlara yakınlaşmaya işaret etmektedir (Oliveira ve ark., 2015). Genel olarak maltodekstrin ilaveli kurutulan örneklerin maltodekstrinsiz kurutulan örneklerden daha düşük a* değerine sahip olduğu belirlenmiştir. Dirim ve ark. (2015) tarafından yapılan çalışmada maltodekstrin ilavesi ile dondurarak kurutulmuş kivi pürelerinde a* değerinin azaldığı tespit edilmiştir. a* değerindeki azalış ayrıca dondurarak kurutma sonrası ürünün öğütülmesi sonucu meyvede bulunan karotenoid bileşenlerinin degradasyonundan kaynaklanmış olabilir (Dağ ve ark., 2017). Mishra ve ark. (2009) farklı yöntemlerin kullanıldığı amla meyve tozu üretiminde en düşük $a^{*}$ değerini dondurarak kurutma yöntemi ile elde ettiği örneklerde tespit etmiştir.

Toz örneklerde $b^{*}$ değerleri 41.91-54.98 arasında tespit edilmiş olup, en yüksek $b^{*}$ değeri maltodekstrinsiz SHK yöntemi ile elde edilen 
örneklerde, en düşük $b^{*}$ değeri ise maltodekstrinsiz DK yöntemi ile elde edilen örneklerde belirlenmiştir $(\mathrm{P}<0.05)$. $\quad \mathrm{b}^{*}$ değerleri taze meyve püresine göre SHK yöntemi ile kurutulan örneklerde artış, DK yöntemi ile kurutulan örneklerde azalış göstermiştir. Dirim vd. (2015) dondurarak kurutulmuş maltodekstrin ilaveli ayva püresi tozlarında $b^{*}$ değerinde azalış tespit etmişlerdir. $b^{*}$ değerinin pozitif değerlere yaklaşması sarılığın artması ve daha az kahverengileşmeye işaret etmektedir (Darvishi ve ark., 2013).

Kroma renk yoğunluğunu ifade eden bir parametredir (Michalska ve ark., 2018). Örneklerin kroma değerleri 42.13-55.17 arasında değişme göstermiştir. En yüksek kroma değeri maltodekstrinsiz SHK yöntemi ile elde edilen örneklerde, en düşük kroma değeri ise maltodekstrinsiz DK yöntemi ile elde edilen örneklerde belirlenmiştir $(P<0.05)$. Kroma değerleri $b^{*}$ değerlerinde olduğu gibi taze meyve püresine göre SHK yöntemi ile kurutulan örneklerde artış, DK yöntemi ile kurutulan örneklerde azalış göstermiştir.

Örneklerin $h^{\circ}$ değerleri 84.40-88.37-arasında tespit edilmiş olup, en yüksek $h^{\circ}$ değeri maltodekstrin ilaveli DK yöntemi ile elde edilen örnekte, en düşük $h^{\circ}$ değeri maltodekstrinsiz DK yöntemi ile elde edilen örnekte belirlenmiştir $(P<0.05)$. Hue açısı değerinin $0^{\circ}, 90^{\circ}, 180^{\circ}$ ve $270^{\circ}$ olması sırasıyla kırmızı, sarı, yeşil ve mavi renk tonlarını ifade etmektedir (İslam ve ark., 2017). Hue açısı değerlerindeki azalma, sarılıktan uzaklaşarak kahverengileşmeye işaret etmektedir (Hawlader ve ark. 2006). Maltodekstrin ilaveli örneklerin $h^{\circ}$ açısı değerlerinin daha yüksek olduğu ve dolayısıyla daha sarı renkte olduğu söylenebilir.

Örneklerin TRD değerleri 14.15-28.45 arasında belirlenmiş olup, taze meyve püresine göre TRD en fazla maltodekstrinsiz DK yöntemi ile kurutulan örneklerde gerçekleşmiştir $(P<0.05)$. En az TRD ise SHK yöntemi ile kurutulan örneklerde tespit edilmiştir. Maltodekstrin, arabik gam, aljinat ve pektin gibi farklı oranlarda ve kombinasyonlarda dondurarak kurutulmuş altın çilek meyve suyu tozlarında, taze meyve suyuna göre TRD, en fazla taşıyıcı ajan kullanılmadan elde edilen dondurarak kurutulmuş meyve suyu tozlarında belirlenmiştir. \%10 maltodekstrin ilavesi ile elde edilen toz örneğinde, dondurarak kurutulmuş örneğe göre TRD azalmıştır (Dağ ve ark., 2017). Kurutma prosesinde renk değişimlerinin en önemli sebepleri esmerleşme reaksiyonları, karotenoid kayıpları, renk pigmentlerinin parçalanması ve Laskorbik asitin okdidasyonudur (Ghanem ve ark., 2012; Ghanem Romdhane ve ark., 2015).

Genel olarak renk değerleri açısından sıcak hava kurutma yöntemi ile elde edilen toz örneklerinin kamkat püresinin renk değerlerine daha yakın değerlerde olduğu gözlenmiştir.

Çalışma sonucunda kamkat tozlarında belirlenen ıslanabilirlik, çözünürlük, yığın yoğunluğu, sıkıştırılmış yoğunluk, akabilirlik ve yapışkanlık özelliklerine ait veriler Çizelge 3’te yer almaktadır. Duncan çoklu karşılaştırma sonuçlarına göre örneklerin ıslanabilirlik süreleri 196-450 s arasında değişmekle birlikte, ıslanabilirlik süreleri arasındaki farklılık önemli bulunmuştur $(P<0.05)$. En yüksek Islanabilirlik süresi maltodekstrin ilaveli DK yöntemi ile elde edilen örnekte, en düşük ise maltodekstrinsiz DK yöntemi ile elde edilen örnekte belirlenmiştir. Her iki yöntemde de maltodekstrinli örneklerin daha yüksek ıslanabilirlik sürelerine sahip olduğu belirlenmiştir. Tucuma meyvesinden farklı taşıyıcı ajan kullanılarak dondurarak kurutma yöntemi ile elde edilen meyve tozlarında ıslanabilirlik süreleri 170-223 s arasında tespit edilmiştir (Silva ve ark., 2018). Dondurarak kurutulmuş \%10 maltodekstrin ilaveli kivi, balkabağı ve ayva tozlarının ıslanabilirlik süreleri 77-186 s arasında tespit edilmiştir (Dirim ve ark., 2015). Bulgularımız literatür değerlerinden yüksektir. Islanabilirlik özelliği toz partiküllerin yüzeylerinden suyu absorplama yeteneği olarak tanımlanmaktadır. Toz ürünlerin ıslanabilirlik özellikleri partikülün alanına, yoğunluğuna, büyüklüğüne ve partikülün yapısında bulunan higroskopik maddelerin içeriği gibi faktörlere göre değişebilmektedir (Schuck, 2011). 
Çizelge 3. Kamkat tozlarının toz ürün özellikleri*

Table 3. The powder properties of kumquat powders*

\begin{tabular}{|c|c|c|c|c|}
\hline $\begin{array}{l}\text { Özellik } \\
\text { Properties }\end{array}$ & $\begin{array}{c}\text { Maltodekstrin ilaveli- } \\
\text { SHK } \\
\text { With maltodextrin- } \\
\text { HAD }\end{array}$ & $\begin{array}{c}\text { Maltodekstrinsiz-SHK } \\
\text { Without maltodextrin- } \\
H A D\end{array}$ & $\begin{array}{l}\text { Maltodekstrin ilaveli- } \\
\text { DK } \\
\text { With maltodextrin-FD }\end{array}$ & $\begin{array}{c}\text { Maltodekstrinsiz-DK } \\
\text { Without } \\
\text { maltodextrin-FD }\end{array}$ \\
\hline $\begin{array}{l}\text { Islanabilirlik (saniye) } \\
\text { Wettability (second) }\end{array}$ & $450.66 \pm 4.04^{b}$ & $240 \pm 2.00^{c}$ & $774.66 \pm 5.03^{\mathrm{a}}$ & $196.33 \pm 1.52^{d}$ \\
\hline $\begin{array}{l}\text { Çözünürlük (saniye) } \\
\text { Solubility (second) }\end{array}$ & $306.33 \pm 3.51^{b}$ & $299.33 \pm 4.04^{c}$ & $414 \pm 4.00^{\mathrm{a}}$ & $230 \pm 2.00^{d}$ \\
\hline $\begin{array}{l}\text { Yığın yoğunluğu (g ml- } \\
\left.{ }^{1}\right) \\
\text { Bulk density }\left(\mathrm{g} \mathrm{ml}^{-1} \text { ) }\right.\end{array}$ & $0.70 \pm 0.005^{\mathrm{a}}$ & $0.67 \pm 0.02^{b}$ & $0.37 \pm 0.005^{c}$ & $0.27 \pm 0.01^{d}$ \\
\hline $\begin{array}{l}\text { Sıkıştırılmış yoğunluk } \\
\left(\mathrm{g} \mathrm{ml}^{-1}\right) \\
\text { Tapped density }\left(\mathrm{g} \mathrm{ml}^{-1}\right)\end{array}$ & $0.73 \pm 0.01^{b}$ & $0.77 \pm 0.02^{\mathrm{a}}$ & $0.67 \pm 0.01^{c}$ & $0.39 \pm 0.01^{d}$ \\
\hline $\begin{array}{l}\text { Akabilirlik (Carl İndex- } \\
\text { Ci) } \\
\text { Flowability (Carl Index- } \\
\text { Cl) }\end{array}$ & $\begin{array}{l}4.50 \pm 1.49^{d} \\
\text { (Çok iyi) }\end{array}$ & $\begin{array}{c}12.75 \pm 5.54^{c} \\
\text { (Çok iyi) }\end{array}$ & $\begin{array}{l}43.78 \pm 0.43^{a} \\
\text { (Kötü) }\end{array}$ & $\begin{array}{c}30.76 \pm 2.28^{b} \\
\text { (Orta) }\end{array}$ \\
\hline $\begin{array}{l}\text { Yapışkanlık (Hausner } \\
\text { Oranı-HO) } \\
\text { Cohesiveness (Hausner } \\
\text { Ratio-HR) }\end{array}$ & $\begin{array}{l}1.04 \pm 0.01^{\mathrm{d}} \\
\text { (Düşük) }^{\text {(D) }}\end{array}$ & $\begin{array}{l}1.14 \pm 0.07^{c} \\
\text { (Düşük) }\end{array}$ & $\begin{array}{c}1.77 \pm 0.01^{\mathrm{a}} \\
\text { (Yüksek) }\end{array}$ & $\begin{array}{l}1.44 \pm 0.04^{b} \\
\text { (Yüksek) }\end{array}$ \\
\hline
\end{tabular}

*Aynı satırdaki farklı harfler ortalamalar arasındaki farkııı̆ın $\mathrm{P}<0.05$ düzeyinde önemli olduğunu gösterir.

* Different letters in the same row indicate that the differences between the means are significant at $P<0.05$.

Örneklerin çözünürlük süreleri $230-414$ s arasında değişmiştir $(\mathrm{P}<0.05)$. En yüksek çözünürlük süresi maltodekstrinli DK yöntemi ile elde edilen örnekte, en düşük ise maltodekstrinsiz DK yöntemi ile elde edilen örnekte belirlenmiştir. Her iki yöntemde de maltodekstrinli kurutulan örneklerin daha uzun sürede çözündükleri belirlenmiştir. DK yöntemi ile elde edilen örneklerin SHK ile elde edilen örneklerden daha uzun sürede çözündüğü belirlenmiştir. Dondurarak kurutulmuş \%10 maltodekstrin ilaveli kivi, balkabağı ve ayva tozlarının ıslanabilirlik süreleri 77-186 s arasında tespit edilmiştir (Dirim vd. 2015). Çalışkan ve Dirim (2013) sumak tozlarında çözünürlük sürelerini $93.5-314.5 \mathrm{~s}$ olarak belirlemiştir. Bulgularımız bu değerlerden farklıdır. Bu durumun kullanılan materyal çeşidi, taşıyıcı ajan konsantrasyonu ve üretim metotlarından kaynaklandığı düşünülmektedir. Toz ürünlerin çözünürlüğü, nem miktarı, partikül boyutu, partiküllerin fiziksel durumu gibi toz ürün özellikleri ile kullanılan hammadde ve taşıyıcı ajan gibi faktörlerden etkilenmektedir (Tontul ve Topuz, 2017). En uzun ıslanabilirlik ve çözünürlük süresine sahip maltodekstrin ilaveli dondurarak kurutulan örneğin nem içeriğinin de en düşük olduğu belirlenmiştir (Çizelge 1).

Kamkat tozu örneklerinin yığın yoğunluğu değerlerinin 0.27-0.70 $\mathrm{g} \mathrm{mL}^{-1}$ arasında değiştiği gözlenmiştir. En yüksek yığın yoğunluğu değeri maltodekstrin ilaveli SHK yöntemi ile elde edilen toz örneğinde, en düşük yığın yoğunluğu değeri ise maltodekstrinsiz DK yöntemi ile elde edilen örnekte belirlenmiştir $(P<0.05)$. Her iki yöntemde de maltodekstrinli kurutulan örneklerin maltodekstrinsiz kurutulan örneklerden daha yüksek yığın yoğunluğu değerine sahip olduğu tespit edilmiştir. Bazı çalışmalarda ise maltodekstrin ilavesinin toz ürünlerin yığın yoğunluğunu düşürdüğü belirtilmiştir (Goula ve Adamopoulos, 2010; Çalışkan ve Dirim, 2013; İslam ve ark., 2017). Çalışmamızda SHK yöntemi ile kurutulan örneklerin daha yüksek yığın yoğunluğuna sahip olduğu belirlenmiştir. Kurutma 
yöntemi ve özellikle kurutma sıcaklıkları toz ürünlerin yığın yoğunluğunu etkileyebilmektedir. Que ve ark. (2008) balkabağı dilimlerini dondurarak ve sıcak hava ile kurutmuş ve öğüterek toz haline getirmişlerdir. Sıcak hava kurutma ile elde edilen tozların (0.59 $\left.\mathrm{g} \mathrm{mL}^{-1}\right)$, dondurarak kurutulmuş tozlardan $\left(0.33 \mathrm{~g} \mathrm{ml}^{-1}\right.$ ) daha yüksek yığın yoğunluğu değerine sahip olduğu tespit edilmiştir. Michalska ve ark. (2016) dondurarak kurutma, vakum kurutma, konvektif kurutma, vakum mikrodalga kurutma ve konvektif ön kurutma- mikrodalga kurutma yöntemleri ile elde edilen erik tozu örneklerinde yığın yoğunluğu değerinin en düşük dondurarak kurutma yöntemi ile elde edildiğini belirtmişlerdir. Araştırmacılar konvektif ve mikrodalga kurutma sonucu elde edilen toz ürünün daha düşük gözeneklilik yapısına sahip olduğunu, dondurarak kurutulan toz örneklerin ise yüksek gözenekli yapısından dolayı düşük yığın yoğunluğuna sahip olduğunu bildirmişlerdir. Yığın yoğunluğu, toz ürünlerin taşınması, depolanması ve ambalajlanmasında önemlidir ve yüksek yığın yoğunluğu değerine sahip toz ürünlerin elde edilmesi düşük paketleme ve taşıma maliyetleri açısından üreticiler tarafından istenen bir özelliktir (Çalışkan ve Dirim, 2013; Dirim ve Talih, 2018). Düşük yığın yoğunluğu değerleri ayrıca toz ürünlerde oksidasyonu arttırarak, ürün stabilitesini azaltabilmektedir (Dantas ve ark., 2018). İslam ve ark. (2017) farklı maltodekstrin konsantrasyonlarında iki farklı yöntemle elde ettikleri portakal suyu konsantresi tozlarında yığın yoğunluğu değerini $0.40-0.54 \mathrm{~g} \mathrm{ml}^{-1}$ olarak tespit etmişlerdir. Goula and Adamopoulos (2010), farklı dekstroz eşdeğerinde ve konsantrasyonlarda maltodekstrin katkılı portakal suyu konsantrelerinden püskürterek kurutma yöntemi ile elde ettikleri toz ürünlerde yığın yoğunluğu değerini 0.14-0.41 $\mathrm{g} \mathrm{ml}^{-1}$ aralığında bulmuşlardır. Sıkıştırılmış yoğunluk açısından değerlendirildiğinde maltodekstrinsiz SHK yöntemi ile elde edilen toz örneğinin diğer örneklerden daha yüksek sıkıştırılmış yoğunluk değerine $\left(0.77 \mathrm{~g} \mathrm{ml}^{-1}\right)$ sahip olduğu kaydedilmiştir $(P<0.05)$. En düşük sıkıştırılmış yoğunluk değeri $\left(0.39 \mathrm{~g} \mathrm{ml}^{-1}\right)$ ise maltodekstrinsiz DK yöntemi ile elde edilen örnekte belirlenmiştir. Kurutma yöntemi sıkıştırılmış yoğunluk değerlerini etkilemiş, SHK yöntemi ile elde edilen örneklerin DK yöntemi ile elde edilen örneklerden daha yüksek sıkıştırıımış yoğunluk değerine sahip olduğu gözlenmiştir. İslam ve ark. (2017) farklı maltodekstrin konsantrasyonlarında elde ettikleri portakal suyu konsantresi tozlarında sıkıştırılmış yoğunluk değerini 0.40-0.54 $\mathrm{g} \mathrm{mL}^{-1}$ olarak tespit etmişlerdir.

Toz gıdaların akabilirlik ve yapışkanlık özellikleri Carr Index ve Hausner oranına göre belirlenmektedir. $\mathrm{Cl}$ ve HR değerleri sırasıyla; <15 (çok iyi), 15-20 (iyi), 20-35(orta) ve 35>(kötü) ve <1.2 (düşük), 1.2-1.4 (orta) ve >1.4 (yüksek) olarak değerlendirilmektedir (Jinapong ve ark., 2008). Duncan çoklu karşılaştırma testi sonuçlarına göre, çalışmamızda toz örneklerin akabilirlik (Ci) değerleri 4.50-43.78 arasında değişmiştir. Maltodekstrinli ve maltodekstrinsiz SHK yöntemi ile elde edilen örneklerin çok iyi akabilirlik değerine sahip olduğu, kötü akabilirlik özelliği gösteren örneğin ise maltodekstrin ilaveli DK yöntemi ile elde edilen örnek olduğu tespit edilmiştir. Toz örneklerin yapışkanlık (HO) değerleri ise 1.04-1.77 arasında tespit edilmiş olup, SHK yöntemi ile elde edilen örneklerin yapışkanlık özelliklerinin DK yöntemi ile elde edilen örneklere göre daha iyi olduğu sonucuna varılmıştır. Elde edilen verilere göre maltodekstrin ilaveli SHK yöntemi ile elde edilen toz örneğinin diğer örneklere göre, yüksek akabilirlik ve düşük yapışkanlık özelliği gösterdiği belirlenmiştir. Dirim ve ark. (2015) tarafından yapılan çalışmada, \%10 maltodekstrin içeren dondurarak kurutulmuş balkabağı ve ayva tozlarının yüksek yapışkanlık ve kötü akabilirlik özellik gösterdiği, kivi tozlarının ise yapışkanlık ve akabilirlik özellikleri açısından orta düzeyde olduğu belirlenmiştir. İslam ve ark. (2017) farklı maltodekstrin konsantrasyonlarında iki farklı yöntemle elde ettikleri portakal suyu konsantresi tozlarında $\mathrm{Cl}$ ve $\mathrm{HO}$ değerlerini sırasıyla $15.96-23.07$ ve $1.19-1.30$ olarak tespit etmişlerdir. Zea ve ark. (2013) tarafından yapılan çalışmada dondurarak kurutulmuş \%10 maltodekstrin katkılı guava ve pitaya tozlarının $\mathrm{HO}$ 
ve Ci değerleri sırasıyla 1.37 ve 27.19 ile 1.53 ve 34.87 olarak belirlenmiştir.

\section{Sonuçlar}

$\mathrm{Bu}$ çalışmada kamkat püresinden maltodekstrin ilaveli ve maltodekstrinsiz olarak sıcak hava kurutma ve dondurarak kurutma yöntemi ile toz üretimi gerçekleştirilmiş ve bu yöntemlerin kamkat tozlarının fizikokimyasal özelliklerine etkisi değerlendirilmiştir. Maltodekstrin ilavesinin ve kurutma yöntemlerinin toz ürünlerin fizikokimyasal özellikleri üzerine etkili olduğu gözlenmiştir. En düşük nem içeriği ve su aktivitesi değeri maltodekstrin ilaveli dondurarak kurutma yöntemi ile elde edilen örnekte belirlenmiştir. Sıcak hava ile kurutulan örneklerin renk stabilitesi açısından daha üstün özellikte olduğu tespit edilmiştir. En düşük ıslanabilirlik ve çözünürlük süresine sahip örneklerin maltodekstrinsiz dondurarak kurutma yöntemi ile elde edilen kamkat tozu örneği olduğu belirlenmiştir. Sıcak hava ile kurutulan tozların yığın yoğunluğu ve sıkıştırılmış yoğunluk değerlerinin daha yüksek olduğu ve özellikle maltodekstrin ilaveli örneğin yüksek akabilirlik ve düşük yapışkanlık özelliği gösterdiği belirlenmiştir. Belirlenen fizikokimyasal özelliklere ek olarak depolama süresi ve koşullarının etkisinin de değerlendirileceği çalışmalar yapılması tavsiye edilmektedir.

\section{Ekler}

Bu çalışma Tarımsal Araştırmalar ve Politikalar Genel Müdürlüğü Hayvan Sağlığı ve Gıda Yem Araştırmaları Daire Başkanlığı tarafından desteklenen projenin (TAGEM/HSGYAD/17/A03/P06/138) bir bölümüdür.

\section{Kaynaklar}

Agudelo, C., Barros, L., Santos-Buelga, C., MartinezNavarrete, N., ve Ferreira, I.C. (2017). Phytocehmical content and antioxidant activity of grapefruit (Star Ruby): A comparison between fresh freeze-dried fruits and different powder formulations. LWT-Food
Science and Technology, 80, 106-112.

AOAC, (2000). Official Method of Analysis AOAC INTERNATIONAL. 17 ${ }^{\text {th }}$ Edition, 986.21 Moisture in Spices, Gaithersburg, MD, USA.

Araujo-Díaz, S. B., Leyva-Porras, C., Aguirre-Bañuelos, P., Álvarez-Salas, C., ve Saavedra-Leos, Z. (2017). Evaluation of the physical properties and conservation of the antioxidants content, employing inulin and maltodextrin in the spray drying of blueberry juice. Carbohydrate polymers, 167, 317325.

Ballesteros, L. F., Ramirez, M. J., Orrego, C. E., Teixeira, J. A., ve Mussatto, S. I. (2017). Encapsulation of antioxidant phenolic compounds extracted from spent coffee grounds by freeze-drying and spraydrying using different coating materials. Food chemistry, 237, 623-631.

Caparino, O. A., Tang, J., Nindo, C. I., Sablani, S. S., Powers, J. R., ve Fellman, J. K. (2012). Effect of drying methods on the physical properties and microstructures of mango (Philippine 'Carabao'var.) powder. Journal of Food Engineering, 111(1), 135148.

Chegini, G. R., ve Ghobadian, B. (2005). Effect of spraydrying conditions on physical properties of orange juice powder. Drying Technology, 23(3), 657-668.

Çalışkan, G., ve Dirim, S. N. (2013). The effects of the different drying conditions and the amounts of maltodextrin addition during spray drying of sumac extract. Food and Bioproducts Processing, 91(4), 539548.

Dağ. D., Kilercioğlu. M., ve Öztop. M. H. (2017). Physical and chemical characteristics of encapsulated goldenberry (Physalis peruviana L.) juice powder. LWT-Food Science and Technology, 83, 86-94.

Dantas, D., Pasquali, M. A., Cavalcanti-Mata, M., Duarte, M. E., ve Lisboa, H. M. (2018). Influence of Spray Drying Conditions on the Properties of Avocado Powder Drink. Food Chemistry, 266, 284-291.

Darvishi, H., Khoshtaghaza, M.H., ve Minaei, S. (2014). Drying kinetics and colour change of lemon slices. Internatıonal Agrophysics, 28,1-6.

Dirim, S.N., ve Çalışkan, G. (2012). Determination of the effect of freeze drying process on the production of pumpkin (Cucurbita Moschata) puree powder and the powder properties. GIda, 37 (4), 203-210.

Dirim, S.N., ve Talih, M. (2018). Kurutma yardımcı maddelerinin dondurarak kurutulmuş taflan tozlarının özellikleri üzerine etkisi. Gıda, 43(3), 461475.

Dirim. S. N., Çalışkan. G., ve Ergün, K. (2015). Dondurularak Kurutulmuş Bazı Meyve Tozlarının Toz Ürün Özelliklerinin Belirlenmesi. Gıda, 40(2), 85-92.

Ferrari, C.C., Germer, S. P. M., ve De Aguirre, J. M. (2012). Effects of spray-drying conditions on the physicochemical properties of blackberry powder. Drying Technology, 30(2), 154-163.

Gabriele, M., Frassinetti, S., Caltavuturo, L., Montero, L., Dinelli, G., Longo, V., Di Gioia, D., ve Pucci, L. (2017). Citrus bergamia powder: antioxidanti antimicrobial and anti-inflammatory properties. Journal of Functional Foods, 31, 255-265. 
García-Salas, P., Gómez-Caravaca, A. M., Arráez-Román, D., Segura-Carretero, A., Guerra-Hernández, E., GarcíaVillanova, B., ve Fernández-Gutiérrez, A. (2013). Influence of technological processes on phenolic compounds. organic acids. furanic derivatives. and antioxidant activity of whole-lemon powder. Food chemistry, 141(2), 869-878.

Ghanem Romdhane, N., Bonazzi, C., Kechaou, N., ve Mihoubi, N. B. (2015). Effect of air-drying temperature on kinetics of quality attributes of lemon (Citrus limon cv. lunari) peels. Drying technology, 33(13), 1581-1589.

Ghanem, N., Mihoubi, D., Kechaou, N., ve Mihoubi, N. B. (2012). Microwave dehydration of three citrus peel cultivars: Effect on water and oil retention capacities, color, shrinkage and total phenols content. Industrial Crops and Products, 40, 167-177.

Gong, Z., Zhang. M., Mujumdar, A.S., ve Sun. J. (2008). Spray drying and agglomeration of instant bayberry powder. Drying Technology, 26, 116-121.

Goula, A. M., ve Adamopoulos, K. G. (2010). A new technique for spray drying orange juice concentrate. Innovative Food Science \& Emerging Technologies, $11(2), 342-351$.

Goula, A.M., ve Adamopoulos. K.G. (2008). Effect of maltodextrin addition during spray drying of tomato pulp in dehumidified air: II. Powder properties. Drying Techonology, 26 (6), 726-737.

Güney, M., Oz, A.T. ve Kafkas, E. (2015). Comparison of lipids, fatty acids and volatile compounds of various kumquat species using HS/GC/MS/FID techniques. Journal of The Science of Food and Agriculture, 95(6), 1268-1273.

Hawlader, M. N. A., Perera, C. O., ve Tian, M. (2006). Properties of modified atmosphere heat pump dried foods. Journal of Food Engineering. 74(3), 392-401.

İslam. M. Z.. Kitamura. Y.. Kokawa. M.. Monalisa. K.. Tsai. F. H., ve Miyamura. S. (2017). Effects of micro wet milling and vacuum spray drying on the physicochemical and antioxidant properties of orange (Citrus unshiu) juice with pulp powder. Food and Bioproducts Processing, 101, 132-144.

Jaya, S., ve Das, H. (2009). Glass transition and sticky point temperatures and stability/mobility diagram of fruit powders. Food and Bioprocess Technology, 2(1), 8995.

Jinapong, N., Suphantharika, M., ve Jamnong, P. (2008). Production of instant soymilk powders by ultrafiltration. spray drying and fluidized bed agglomeration. Journal of Food Engineering, 84, 194-205.

Kadam, D. M., Rai, D. R., Patil, R. T., Wilson, R. A., Kaur, S., ve Kumar, R. (2011). Quality of fresh and stored foam mat dried Mandarin powder. International journal of food science \& technology, 46(4), 793-799.

Kang, H. J., Chawla, S. P., Jo, C., Kwon, J. H., ve Byun, M. W. (2006). Studies on the development of functional powder from citrus peel. Bioresource technology, 97(4), 614-620.

Karam, M. C., Petit, J., Zimmer, D., Djantou, E. B., ve Scher, J. (2016). Effects of drying and grinding in production of fruit and vegetable powders: A review. Journal of Food Engineering, 188, 32-49.
Lou, S. N., Lai, Y. C., Huang, J. D., Ho, C. T., Ferng, L. H. A. ve Chang, Y. C. 2015. Drying effect on flavonoid composition and antioxidant activity of immature kumquat. Food Chemistry, 171, 356-363.

Michalska, A., Wojdyło, A., Honke, J., Ciska, E., ve Lauer, W. (2018). Drying-induced physico-chemical changes in cranberry products. Food Chemistry, 240, 448-455.

Michalska. A., Wojdyło. A., Lech. K., Łysiak. G. P. ve Figiel. A. (2016). Physicochemical properties of whole fruit plum powders obtained using different drying technologies. Food chemistry, 207. 223-232.

Mishra, P., Srivastava, V., Verma, D., Chauhan, O. P., ve Rai, G. K. (2009). Physicochemical properties of chakiya variety of amla (emblica officinalis) and effect of different dehydration methods on quality of powder. African Journal of Food Science, 3(10), 303-306.

Oliveira, D. M., Lima, C. G., Clemente, E., Afonso, M. R. A., Costa, J. M. C. D. (2015). Stability of bioactive compounds and quality parameters of grugru palm powder (Acrocomia Aculeata) in different drying conditions. Journal of Food Quality, 38(2), 94-102.

Que, F., Mao, L., Fang, X., ve Wu, T. (2008). Comparison of hot air-drying and freeze-drying on the physicochemical properties and antioxidant activities of pumpkin (Cucurbita moschata Duch.) flours. International journal of food science \& technology, 43(7), 1195-1201.

Quek, S. Y., Chok, N. K., ve Swedlund, P. (2007). The physicochemical properties of spray-dried watermelon powders. Chemical Engineering and Processing: Process Intensification, 46(5), 386-392.

Rahman, M.S.A.S., Bengtsson, Q.H., Sablani, S.S., ve AlAlawi, A. (2009). Drying kinetics and allicin potential in garlic slices during different methods of drying. Drying Technology, 27 (3), 467e477.

Sablani, S.S., (2006). Drying of fruits and vegetables: retention of nutritional/functional quality. Drying Technology, 24 (2), 123e135.

Sablani, S.S., Andrews, P.K., Davies, N.M., Walters, T., Saez, H., ve Bastarrachea, L. (2011). Effects of air and freeze drying on phytochemical content of conventional and organic berries. Drying Technology, 29 (2), $205 \mathrm{e} 216$.

Sablani. S. S., Shrestha. A. K., ve Bhandari. B. R. (2008). A new method of producing date powder granules: Physicochemical characteristics of powder. Journal of Food Engineering, 87(3), 416-421.

Sadek, E.S., Makris, D.P., ve Kefalas, P. (2009). Polyphenolic composition and anitoxidant characteristics of kumquat (Fortunella margarita) peel fractions. Plant foods for human, 64(4), 297-302.

Saifullah, M., Yusof, Y. A., Chin, N. L., ve Aziz, M. G. (2016). Physicochemical and flow properties of fruit powder and their effect on the dissolution of fast dissolving fruit powder tablets. Powder technology, 301, 396404.

Schuck, P. (2011). Milk Powder: Physical and Functional Properties of Milk Powders. İn: Encyclopedia of Dairy Sciences. 2nd ed. Vol. 2. J. W. Fuquay. P. F. Fox and P. L. H. McSweeney. ed. Elsevier. Academic Press. London. UK. Pp. 117-124

Si, X., Chen, Q., Bi, J., Wu, X., Yi, J., Zhou, L., Li, Z. (2015). 
Comparison of different drying methods on the physical properties. bioactive compounds and antioxidant activity of raspberry powders. Journal of the Science of Food and Agriculture, 96 (6), 2055-2062.

Silva, R. S., Santos, C. D. L., Mar, J. M., Kluczkovski, A. M., Figueiredo, J. D. A., Borges, S. V., ... ve Campelo, P. H. (2018). Physicochemical properties of tucumã (Astrocaryum aculeatum) powders with different carbohydrate biopolymers. LWT, 94, 79-86.

Suravanichnirachorn, W., Haruthaithanasan. V., Suwonsichon. S., Sukatta. U., Maneeboon. T., ve Chantrapornchai. W. (2018). Effect of carrier type and concentration on the properties. anthocyanins and antioxidant activity of freeze-dried mao (Antidesma bunius (L.)) Spreng] powders. Agriculture and Natural Resources,1-7.

Tontul, i.., ve Topuz, A. (2017). Spray-drying of fruit and vegetable juices: effect of drying conditions on the product yield and physical properties. Trends in food science \& technology, 63, 91-102.
Wang, J., Li, Y. Z., Chen, R. R., Bao, J. Y., ve Yang, G. M. (2007). Comparison of volatiles of banana powder dehydrated by vacuum belt drying, freeze-drying and air-drying. Food Chemistry, 104(4), 1516-1521.

Wang, Y.W., Zeng, W.C., Xu, P.Y., Lan, Y.J., Zhu, R.X., Zhong, K., Huang, Y.N. ve Gao, H. (2012). Chemical composition and antimicrobial activity of the essential oil of Kumquat (Fortunella crassifolia Swingle) Peel. International Journal of Molecular Sciences, 13, 3382-3393.

Zea, L. P., Yusof, Y. A., Aziz, M. G., Ling, C. N., ve Amin, N. A. M. (2013). Compressibility and dissolution characteristics of mixed fruit tablets made from guava and pitaya fruit powders. Powder technology, 247, 112-119.

Zorić, Z., Pelaić, Z., Pedisić, S., Garofulić, I. E., Kovačević, D. B., ve Dragović-Uzelac, V. (2017). Effect of storage conditions on phenolic content and antioxidant capacity of spray dried sour cherry powder. LWTFood Science and Technology, 79, 251-259. 